\title{
TEMPORAL SHIFT OF BAGMATI RIVER OVER 25 YEARS USING LANDSAT
}

\author{
A. Subedi ${ }^{1}$, P. Poudel ${ }^{2}$, T. D. Acharya ${ }^{3,4, *}$ \\ ${ }^{1}$ Institute of Forestry, Pokhara Campus, Tribhuvan University, Pokhara 33700, Nepal- anojsubedi99@gmail.com \\ ${ }^{2}$ Himalayan College of Agricultural Sciences \& Technology Purbanchal University, Kathmandu 44600, Nepal- \\ poudelprati@gmail.com \\ ${ }^{3}$ Dept. of Civil Engineering, Kangwon National University, Chuncheon 24341, Korea - tridevacharya @kangwon.ac.kr \\ ${ }^{4}$ School of Geomatics and Urban Spatial Information, Beijing University of Civil Engineering and Architecture, Beijing 102616, \\ China
}

Commission V, WG V/7 \& Commission IV, WG IV/6

KEY WORDS: River, RS, GIS, Landsat 8, NDWI, Temporal Shift

\begin{abstract}
:
Bagmati River has been a terrific boon in different aspects like natural, cultural, ecological, etc. However, the river has been in a critical situation with the shift in its quality and quantity during these years. Since the changes are slow-growing, actual shifts are barely noticed. While the in-situ analysis and experimentation become costly, the analysis of Landsat images acquired with the application of Remote Sensing (RS) and Geographic Information System (GIS) provides an inexpensive technique in estimating and mapping such temporal shift in the river. Concerning the case, this study modelled the temporal changes of the Bagmati River within 25 years (1991-2016) using the multi-temporal Landsat images. We adopted the Normalized Difference Water Index (NDWI for the unsupervised extraction of the water feature and monitoring the changes. A model was developed in Arc-GIS by discerning the river, and the difference was determined for 25 years. The result indicated a major temporal shift in the river channel with a decreasing trend from 1991 to 2016. Over 25 years, the river loss almost one-third of its original water-flow channel with a severe sweep in the south-western portion of the study area. With this precise information, a field-based study can be undertaken either to analyse the damage caused by the river in those particular portions or to assess the factors affecting the river shift. Hence, we strongly recommend employing the cost-effective methods, RS and GIS, for detecting, analysing and monitoring the shifts and changes in the rivers and lakes over a while.
\end{abstract}

\section{INTRODUCTION}

Nepal, a country rich in its water resource, encompasses more than 6000 rivers originated from the lap of majestic Himalayas. These major sources of water not only provide fresh water to fulfil the basic needs of people, but also plays equally important role in other major aspects like drinking water, agriculture, electricity production, transportation etc. Water habitats to a raft of flora and fauna and helps in the preservation of biodiversity in the riparian or wetland ecosystem (Vörösmarty et al., 2010). Thus, they are recognized as critical as breathing-air for sustaining all life forms. Rivers have been important assets in the regulation of natural water cycle, climatic regulation as well as other ecological cycles. The same services are provided by the Bagmati River.

Bagmati is not only regarded as the holy river but also considered the source of Nepalese civilization and urbanization. Besides having variable utilities in different aspects like aesthetic, scenic, drinking water, etc. the river, since passes through the most populated city: Kathmandu, quality has been disastrously impaired in the recent years. Because of varied factors like climate change, natural disasters, environmental hazards, undesirable anthropogenic influences, etc., both quality and quantity have been substantially decreased. These challenges the river has been facing since long has been overlooked by the concerned authorities, due to which it has been restrained towards the adversity. The river shape, size, and water volume are changing. Such variation consequently hampers, in one way or another, to other natural resources, environment as well as humans and their assets too. These shifts, however, are slow and takes a long time, thus posed great difficulty in taking rapid measures. Hence, long historic data available provides a clear insight of how these changes are taking place, the trends and even future predictions to prevent changes.

These changes can be studied and examined through the fieldbased experimentation and analyzation but are inordinately costly. Thus, relying on information acquired through the use of remote sensing and geographic information system, this dynamism could easily be identified, at a very low cost, precisely. Therefore, to efficiently detect the existence of water in a river, to extract its actual extent, quantify volume, to predict the embankment shifts, and to constantly monitor its spatio-temporal dynamics has been very crucial. Remote sensing satellites like LANDSAT, SPOT, IKONOS, QUICK $\mathrm{BIRD}$, etc. have been continuously observing the earth. They provide very reliable, accurate and cost-effective information for various changes happening in the earth. Landsat series data are the most widely used optical sensors for measuring and mapping water bodies because of the free and continuous accessibility of high-resolution remote sensing images. Optical sensors have been widely used due to the availability and the suitability of spatial and temporal resolutions (Huang et al., 2015).

Corresponding author 
The surface waters are mercurous and undergo shrink, expansion or shifts in its appearance during the time owing to various natural and human-induced factors (Karpatne et al., 2016). Remote sensing has been prevalent in detecting the changes of surface water like a river, lakes, flood detection and prediction, large scale Spatio-temporal change detection of other water reservoirs (Acharya et al., 2019a).

Multi-temporal remote sensing images provide the basis for monitoring surface water (Mueller et al., 2016; Schaffer-Smith et al., 2017). A plethora of methods has been developed for extracting water areas from optical remote sensing imagery. Either supervised or unsupervised method of classification can be adapted for deriving and generating land cover maps, through which weater areas could be delineated easily (Manavalan et al., 1993; Ozesmi, Bauer, 2002; Acharya et al., 2018; Acharya et al., 2019b). Among such, unsupervised classification methods, including the spectral water extraction methods, are commonly used for water body extraction procedures as these produce impressive results with the Landsat images (Tulbure, Broich, 2013). The water index method, an easy and effective way to extract water body, identifies the difference between water and non-water area.

NDWI is one of the widely adopted indexes for water features extraction and as well as monitoring the changes in the water bodies which precisely highlights the subtle differences between water and non-water areas. It provides information both on the spatial distribution of the water stress and its temporal evolution over longer time periods and assists in improving the accuracy in retrieving the vegetation water content (Ceccato et al. 2001). Similarly, it is a good indicator for liquid water content identification and is less sensitive to atmospheric scattering effects (Gao, 1996; Delbart et al. 2005, Jackson et al. 2004)NDWI employs green band and NIR band (McFeeters, 1996). The value of NDWI ranges from -1 to 1 ; water features are likely to have positive values, but terrestrial vegetation and bare soil generally have negative values. Therefore, 0 is often considered a default threshold for the NDWI results.

In this study, we analyse the image-data from satellite image (Landsat-series images) and geographical information system (GIS) to find the temporal chift in the Bagmati river. Between supervised and unsupervised methods of image classification and the analysis,we used the NDWI method to detect and monitor the temporal shift of the Bagmati River for a period of 25 years using the Landsat series data of 1991, 2002 and 2016. A model was developed in the Arc GIS after detecting the differences using the index method and the change was identified.

\section{EXPERIMENTS}

2.1 Test site: A geographical area between $26.7385^{\circ} \mathrm{N}$ to $27.1824^{\circ} \mathrm{N}$ latitude and $85.2755^{\circ} \mathrm{E}$ to $85.5359^{\circ} \mathrm{E}$ longitude was selected as the study site. The area incorporates the Bagmati River: the site where we analysed the temporal shift. The river separates the two major districts: Rautahat and Sarlahi. The study area with the Bagmati River is shown in Figure 1.

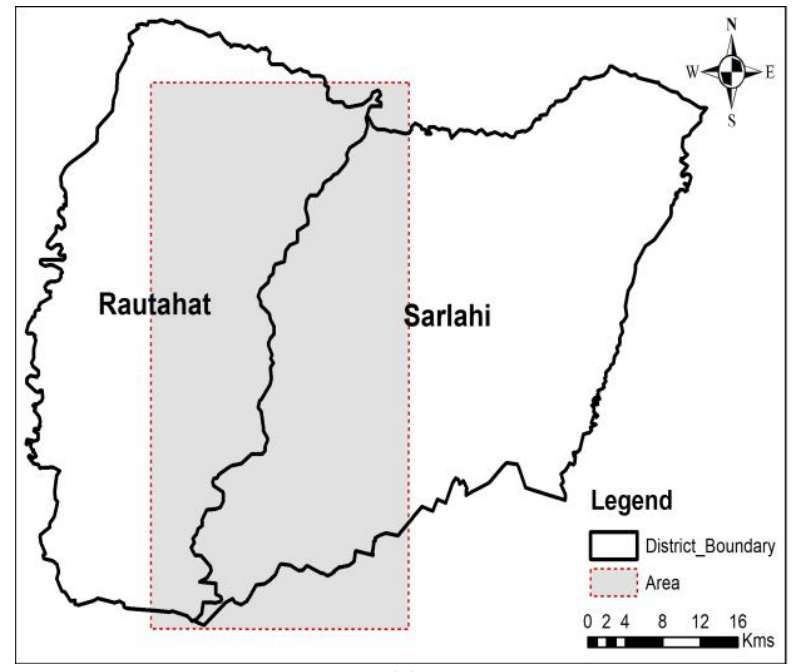

(a)
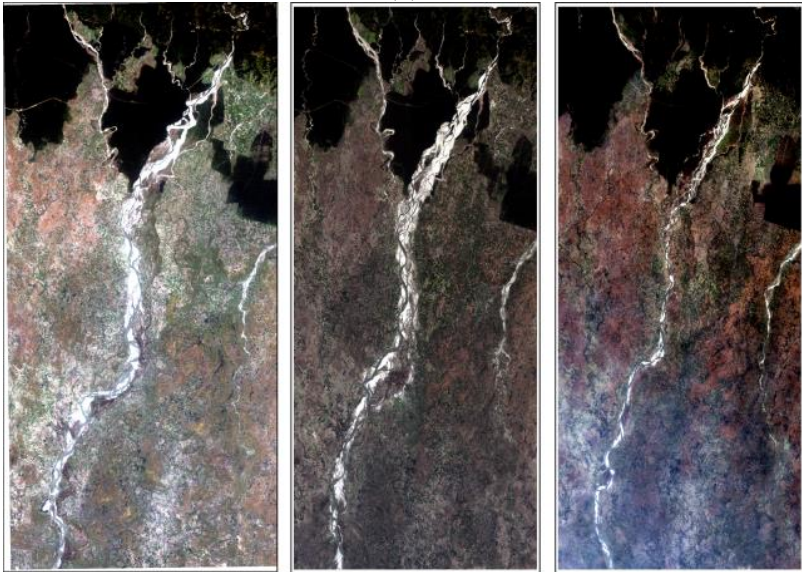

(b)

Figure 1. Map of study area showing a) district boundary and b) Natural colour composite image of the Landsat imagery for 1991, 2002 and 2016 from left to right.

2.2 Data: The data acquired by Landsat series available from the USGS GLOVIS portal were used as the data in the study. Three images from 1991 to 2016, a 25 years gap data, were used for the study of a temporal shift of the Bagmati River within the study area. Those images were acquired by the same satellite and were, thus, chosen such that they were from the same season of the year. This procedure kept the images wellmatched spatially and temporally so that the accuracy increases (Dai, Khorram, 1998).

2.3 Methods: The accessed image file was subjected towards eliminating radiometric as well as a geometric aberration, if any. Subsequently, the area of interest (Bagmati River) was delineated in the software. The images, pre-georeferenced to the Universal Transverse Mercator zone 45 north, were exported into the GeoTIFF format for further analysis.

After the pre-processing step, all three images of the corresponding year were used in the Arc Map for calculating the NDWI. A model was developed in ArcGIS for the unsupervised change detection, recognized as the prioritized option for achieving the Spatio-temporal monitoring of the river dynamics, thus, the McFeeters's formula for NDWI, 
employing the green band and NIR band, was used for the calculation as follows:

$$
\text { NDWI }=\frac{\rho \text { Band2 }-\rho \text { Band4 }}{\rho \text { Band2 }-\rho \text { Band4 }}
$$

where $\rho$ Band $2=$ Reflectance value of the green band $\rho$ Band $4=$ Reflectance value of the NIR band

\section{RESULTS AND DISCUSSION}

The ordinary naked-eye view of the pansharpened Landsat images showed the tentative changes in the body of the whole river channel; this depicted the river is certainly shifting being narrower from the base year to the present. Harmoniously, the temporal analysis of the river within the period between 1991 and 2016 also suggested the shrinkage of the water surface during the period in the Bagmati River which can be seen from the figure 2 .

A comparative study of the river, through the unsupervised classification, indicated a major shift in the Bagmati River channel with a decreasing trend from 1991 to 2016 as can be seen in Figure 3.The surface of the Bagmati River was seen and found through the NDWI index anlysis- quite wide in its extension in 1991 in comparison to other two year. The overall surface are coverage of the river was found to be $32.80 \mathrm{sq} . \mathrm{km}$, which was the highest among the compared with other two years. In 2002, on the another hand, the area of the surface water of the Bagmati River sharank to become 28.34 sq. km which dramatically reduced to $11.99 \mathrm{sq} . \mathrm{km}$ in 2016 along with drastic fluctuations in the water-current flow channel. In the first decade, i.e. from 1991 to 2002, Bagmati River is confirmed to have shrank $0.45 \mathrm{sq} . \mathrm{m} /$ year; where as in the another 15 years of period (2002-2016), the river is shrinking with the more higher rate : 1.09 sq. $\mathrm{m} /$ year. The river is, thus, having the constant displacement and shrinkage in the bank and the water availability. Not only the river is shrinking in terms of the area, but the river channel is erratically fluctuating from the base year to present. (a)

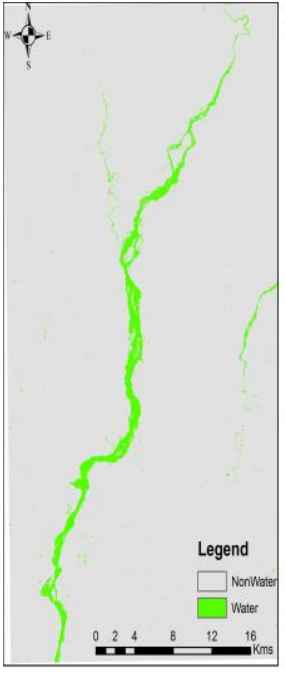

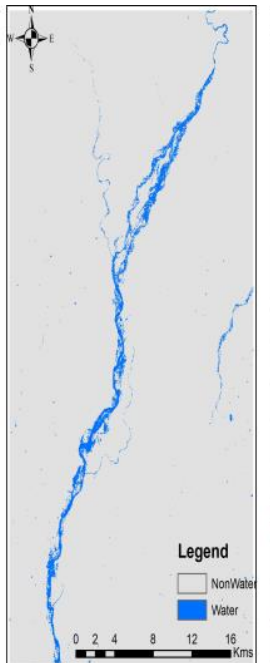

(b)

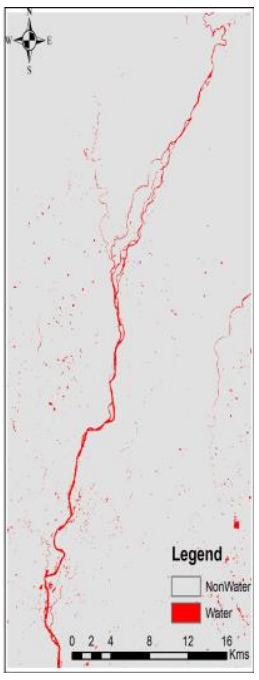

(c)
Figure 2. Detected river surface for the years a) 1991 b) 2002 c) 2016
While the meanderings of the river in the other sections of the river showed low dynamism, a very distinct change of the Bagmati river channel is found in the mid- south-western portion during each of the years. Even though the surface area of the river has shrank to intolerable range, the channel displacement of the subsequent year are overlapping the previous. However, river channel of the year 1991, in the south-western section, has disparate channel for approximately 7 kilometers. The subsequent year, i.e. 2002 has the river channel distinctly deviating from the channel of the former period.

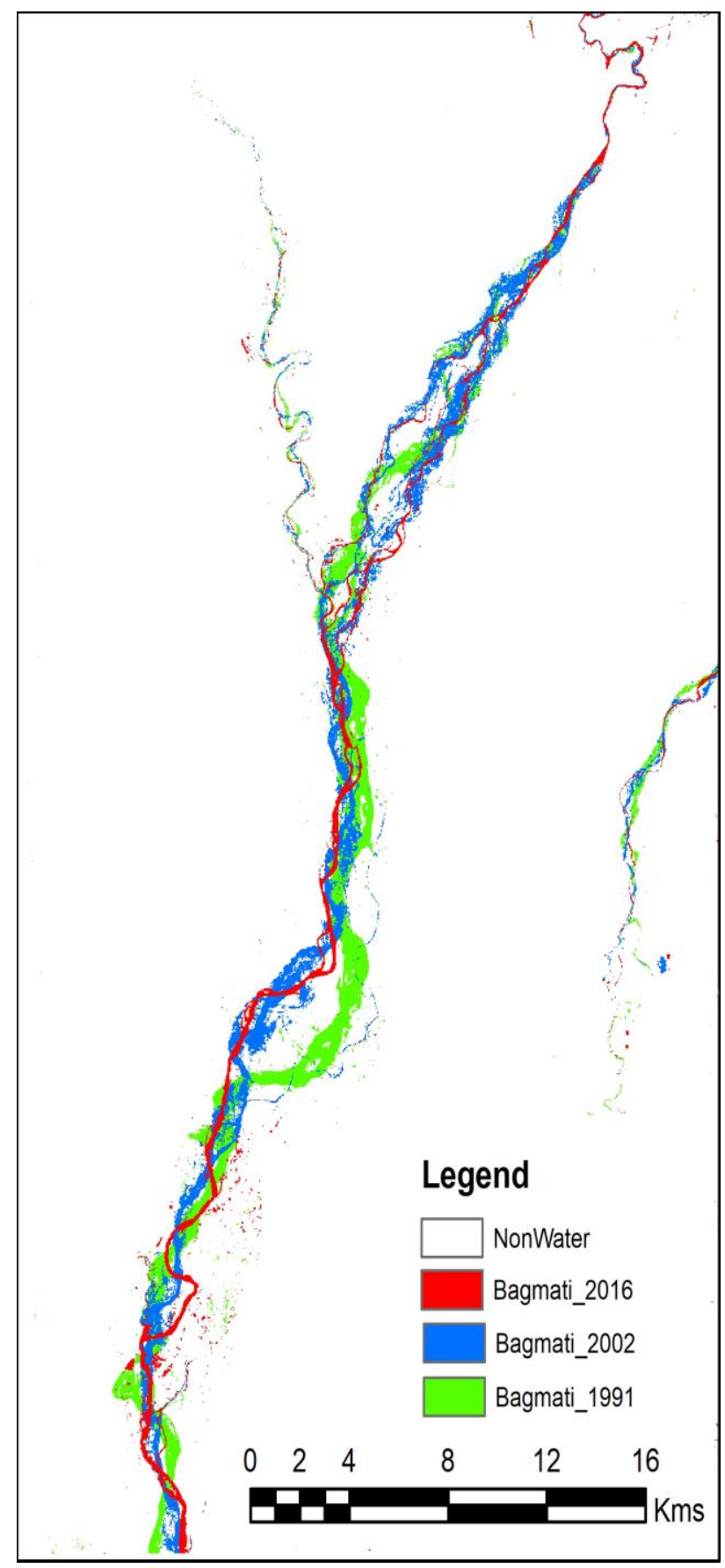

Figure 3. A map showing the changes during the 25-year period, comparatively 
This result, overall, connotes the loss of about one-third of original water-flow channel by the river, just within the 25 years of period, with a severe sweep in the south-western portion of the study area. This suggests, on the one hand, that there must be several factors which have heightened such displacement and shifts in the river. These factors may range from the series of natural hazards to the range of anthropogenic agents. The changing climate in the global scale resulting severe drought and aridity throughout the long period of time may be the most compelling natural cause, whereas unmanaged human-water-utilization practices, artificial river channelization, excavation, etc. could be the artificial reasons. On the other hand, such shifting might have resulted dire ramifications in the particular area where the river is seen shifting at a greater extent. It may have marred the natural integrity of the site as well as the life of many different creatures including the humans. This paves way for the further analysis through the general field based study and analysis.

Concerning the performance of the unsupervised classification, the NDWI performed well in the detection, delineation, and shift identification of the surface water. This index could be used in the similar approaches of detecting and monitoring the changes in the rivers, lakes, and other water sources.

\section{CONCLUSION}

In our study, we used the unsupervised index method of classification which showed good change effects in the overall surface coverage of the Bagmati River. "The Bagmati River is shrinking at the greatest rate", is what our result showed. These sweeping and shrinking trend of the Bagmati River during just 25 year period is the indication of the vulnerability of the river. The river may ultimately, if the situation persists and the river goes losing the coverage in the same rate, will be bereft of water. Thus, appropriate policies, laws, planning and other research and analysis must be carried out for the constant monitoring of the river and preserving our greatest natural assets. The risk zone delineation and identification for the people

Such results can be a useful in monitoring the river system as well as planning for the future actions, most importantly in the countries like Nepal where field-based-sophisticated research and analysis are barely prone to happen. Constant River monitoring, risk zone mapping, disaster risk area identification and prediction, etc. could be effective way to minimize the uncertain risk to living creatures and to keep the water conserved. The series of Landsat images are, therefore, totally useful in discerning the shifts in the river, lakes, and other water bodies. Hence, we strongly recommend employing the cost-effective methods: RS and GIS, for detecting, analysing and monitoring the shift and changes in the rivers and lakes over a while.

\section{ACKNOWLEDGEMENTS}

We are thankful to USGS for providing free access to Landsat images. We express our sincere gratitude to Ashok Subedi and Arjun Subedi for their support and improvisation from data mining to the data analysis.

\section{REFERENCES}

Acharya, T.D., Subedi, A., Huang, H. and Lee, D.H., 2019a. Application of Water Indices in Surface Water Change Detection Using Landsat Imagery in Nepal. Sens. Mater, 31, 1429-1447. https://doi.org/10.18494/SAM.2019.2264.

Acharya, T.D., Subedi, A. and Lee, D.H., 2019b. Evaluation of Machine Learning Algorithms for Surface Water Extraction in a Landsat 8 Scene of Nepal. Sensors, 19(12), p.2769. doi:10.3390/s19122769.

Acharya, T., Subedi, A. and Lee, D., 2018. Evaluation of Water Indices for Surface Water Extraction in a Landsat 8 Scene of Nepal. Sensors, 18(8), p.2580.

Ceccato, P., Flasse, S., Tarantola, S., Jacquemond, S., Gregoire, J.M. 2001. Detecting vegetation water content using reflectance in the optical domain. Re. Sens. of Env. 77: 22-33.

Dai, X., Khorram, S. 1998. The effects of image misregistration on the accuracy of remotely sensed change detection. IEEE Transactions on Geoscience and Remote Sens., 36(5), 15661577.

Delbart, N., L. Kergoat, T. L. Toan, J. Lhermitte, and G. Picard (2005). Determination of phenological dates in boreal regions using normalized difference water index. Re. Sens. of Env., 97: 26-38

Gao, B.C. 1996. NDWI - A normalized difference water index for remote sensing of vegetation liquid water from space. Re. Sens. of Env., 58: 257-266.

Huang, C., Chen, Y., Wu, J., Li, L., \& Liu, R., 2015. An evaluation of Suomi NPP-VIIRS data for surface water detection. Remote Sens. Letters, 6(2), 155-164. https://doi.org/10.1080/2150704X.2015.1017664

Jackson, T.J., Chen, D., Cosh, M., Li, F., Anderson, M., Walthall, C., Doriaswamy, P., Hunt, E.R. 2004. Vegetation water content mapping using Landsat data derived normalized difference water index for corn and soybeans. Re. Sens. of Env., 92: 475-482.

Karpatne, A., Khandelwal, A., Chen, X., Mithal,V., Faghmous, J., Kumar, V.2016. Global monitoring of inland water dynamics: State-of-the art, challenges, and opportunities. In Studies in Computational Intelligence, 645, 121-147. https://doi.org/10.1007/978-3-319-31858-5_7

Manavalan, P., Sathyanath, P., Rajegowda, G. L. 1993. Digital image analysis techniques to estimate water spread for capacity evaluations of reservoirs. Photogrammetric Engineering and Remote Sens., 59(9), 1389-1395.

McFeeters, S. 1996. The Use of the Normalized Difference Water Index (NDWI) in the Delineation of Open Water Features. International Journal of Remote Sens., 17, 14251432. doi:10.1080/ 01431169608948714.

Mueller, N., Lewis, A., Roberts, D., Ring, S., Melrose, R., Sixsmith, J., et al. 2016. Water observations from space: Mapping surface water from 25 years of Landsat imagery 
across Australia. Remote Sens. of Environment, 174, 341-352. https://doi.org/10.1016/j.rse.2015.11.003

Ozesmi, S. L., Bauer, M. E. 2002. Satellite remote sensing of wetlands. Wetlands Ecology and Management, 10(5), 381402. https://doi.org/10.1023/a:1020908432489

Schaffer-Smith, D., Swenson, J. J., Barbaree, B., Reiter, M. E. 2017. Three decades of Landsat-derived spring surface water dynamics in an agricultural wetland mosaic; Implications for migratory shorebirds. Remote Sens. of Environment, 193,180192. https://doi.org/10.1016/ j.rse.2017.02.016

Tulbure, M.G., Broich, M. 2013. Spatio-temporal dynamic of surface water bodies using Landsat time-series data from 1999 to 2011. ISPRS Journal of Photogrammetry and Remote Sens., 79, 44 -52. https://doi.org/10.1016/j.isprsjprs.2013.01.010

Vörösmarty, C. J., Green, P., Salisbury, J., Lammers, R. B. 2000. Global water resources: Vulnerability from climate change and population growth. Science, 289(5477), 284-288. https://doi.org/10.1126/science.289.5477.284 